\title{
Naltrexone at low doses upregulates a unique gene expression not seen with normal doses: Implications for its use in cancer therapy
}

\author{
WAI M. LIU, KATHERINE A. SCOTT, JAYNE L. DENNIS, ELWIRA KAMINSKA, \\ ALAN J. LEVETT and ANGUS G. DALGLEISH \\ Department of Oncology, Institute for Infection and Immunity, \\ St. George's University of London, London SW17 ORE, UK
}

Received March 30, 2016; Accepted May 23, 2016

DOI: $10.3892 /$ ijo.2016.3567

\begin{abstract}
It has been reported that lower doses of the opioid antagonist naltrexone are able to reduce tumour growth by interfering with cell signalling as well as by modifying the immune system. We have evaluated the gene expression profile of a cancer cell line after treatment with low-dose naltrexone (LDN), and assessed the effect that adapting treatment schedules with LDN may have on enhancing efficacy. LDN had a selective impact on genes involved with cell cycle regulation and immune modulation. Similarly, the pro-apoptotic genes BAD and BIK1 were increased only after LDN. Continuous treatment with LDN had little effect on growth in different cell lines; however, altering the treatment schedule to include a phase of culture in the absence of drug following an initial round of LDN treatment, resulted in enhanced cell killing. Furthermore, cells pre-treated with LDN were more sensitive to the cytotoxic effects of a number of common chemotherapy agents. For example, priming HCT116 with LDN before treatment with oxaliplatin significantly increased cell killing to $49 \pm 7.0$ vs. $14 \pm 2.4 \%$ in cultures where priming was not used. Interestingly, priming with NTX before oxaliplatin resulted in just $32 \pm 1.8 \%$ cell killing. Our data support further the idea that LDN possesses anticancer activity, which can be improved by modifying the treatment schedule.
\end{abstract}

\section{Introduction}

A number of reports have identified a putative anticancer role for naltrexone when used at doses lower than those conventionally administered (1). In particular, it has been shown

Correspondence to: Dr Wai Liu, Department of Oncology, Institute for Infection and Immunity, St. George's University of London, 2nd Floor, Jenner Wing, London SW17 0RE, UK

E-mail:wliu@sgul.ac.uk

Key words: naltrexone, low-dose naltrexone, gene expression, priming, recovery phases, cell cycle that these low doses of naltrexone (LDN) are able to suppress tumour growth. A definitive mechanism of action has yet to be established, but what is known is that the effect can be via modifications to the host immune system rendering it more anticancer in nature, or through direct antagonism of tumour growth. Naltrexone, being a specific antagonist of the opioid receptors, can influence the activity of intracellular signalling pathways found downstream of the $G$ protein-coupled receptor. As the net actions of these pathways determine the fate of cells, naltrexone, as well as other opiates, is able to alter cellular function, and induce cell death (2-5). Indeed, in addition to their universally accepted analgesic qualities, the opioids have also been widely reported to elicit a number of other cellular responses that lead to reductions in tumours.

Studies investigating the intracellular effects of naltrexone noted that the mechanism underlying the action of opioids generally involved, in part, modulation of the PI3-kinase cascade $(6,7)$. This suggested that these agents may be able to influence the growth and survival of cancer cells. However, the literature surrounding this is still very unclear, and can be contradictory. Reports have simultaneously shown the archetypal opiate morphine is able to both inhibit the growth of cancer cells as well as to stimulate them in vitro. As some of these cancer cell lines express relatively low levels of the opioid receptors (8), the effects on growth may be independent of them. Furthermore, as both the pro- and anticancer effects have been seen in animal model systems with intact immunity, it has been postulated that morphine may affect the immune response (9), although, this remains inconclusive (10).

Naltrexone has been demonstrated to have a very diverse range of effects on cells. Some are pro-survival in nature such as the induction of proliferation and protection against cell death, whereas others are associated with growth inhibition and the induction of apoptosis. This diversity has made it difficult to establish the principal mechanism of action. The ultimate consequence of treatment with naltrexone however, appears to be determined by dose and schedule (6). Essentially, naltrexone exhibits non-cytotoxic anticancer activities and as such, may be best combined with other modalities and combination schedules that maximise the individual action of each partner (11). Furthermore, the use of drugs concomitantly may 
allow the individual elements to prime for the effects of another and result in a therapeutic synergy. These schedules may also involve adaptations in the sequence in which the agents are employed, and is especially true if the strategy involves a combination of a chemotherapy and an immune adjuvant (11). Determining the best combinatorial partner for naltrexone requires careful consideration, as drugs with characteristics that are unsuitable together can result in antagonism, disruption to the effects of the individual drugs and consequential loss of overall activity.

Here, we describe part of our ongoing studies that explore the anticancer properties of agents that are not cytotoxic nor typically anticancer in application. We have performed a gene expression screen in a cancer cell line previously used to study other known anticancer drugs to determine the profile of naltrexone action. Specifically, we have studied the genetic impact when used at a dose that is typically employed clinically as well as at a lower concentration. Using this information, we then examined the effect that different treatment strategies and schedules have on the efficacy of this drug in vitro.

\section{Materials and methods}

Cell culture and drugs. All cell lines were purchased from the European Collection of Cell Cultures (Salisbury, UK), and maintained and grown in the culture medium specified by the depositor. Specifically, the principal cell lines used in this study were HCT116 (human colorectal cancer) and A549 (human lung cancer), which were cultured in DMEM (Sigma) supplemented with $10 \%$ fetal bovine serum (FBS: Life Technologies, Paisley, UK) and $2 \mathrm{mM}$ L-glutamine (Life Technologies). All cells were grown in a humidified atmosphere with $5 \% \mathrm{CO}_{2}$ in air at $37^{\circ} \mathrm{C}$, and discarded after $\sim 12$ passages. Authentication of the cell lines was performed by the service providers using the AmpFISTR Identifier Plus PCR amplification kit looking for the presence of $<10$ known loci for each cell line.

Naltrexone hydrochloride (naltrexone), cyclophosphamide (CPM), gemcitabine (GEM) and oxaliplatin (OXP) (all Sigma Ltd., Dorset, UK) were dissolved in DMSO, with the final DMSO concentration in individual tests being $<0.05 \%$. Preliminary studies suggested the action of naltrexone was dependent upon concentration; therefore, two concentrationranges were assessed. Conventional doses were $>1 \mu \mathrm{M}$ and designated as NTX, whilst low doses of naltrexone (LDN) were $<100 \mathrm{nM}$. Typical NTX concentrations were 1 and $10 \mu \mathrm{M}$, whereas LDN concentrations were 3-log lower being 1 and $10 \mathrm{nM}$.

RNA extraction and microarray analysis. The genomic arm of this study followed a similar path to one we have published a number of times (12-15). Briefly, exponentially growing cells were seeded into 6-well plates (BD Biosciences, Oxford, UK) at a concentration of $2 \times 10^{5} /$ well and were left to adhere overnight. Cells were then treated for $4 \mathrm{~h}$ with NTX $(10 \mu \mathrm{M})$ or LDN (10 $\mathrm{nM})$, before RNA was extracted and processed as described previously (13).

Samples were then processed for microarray analysis according to the methodologies detailed previously (13). Briefly, equal amounts of biotinylated cRNA was hybridised to the Illumina human HT12-v3 arrays (Applied Biosystems,
Warrington, UK) for $18 \mathrm{~h}$ and subsequently processed according to manufacturer's instructions before scanning on an Illumina BeadArray Reader (Applied Biosystems). The image data were processed using default values in GenomeStudio v2009.1 with imputation of missing data, before loading onto GeneSpring v9.0 for data normalisation and filtering. A $>0.25$-fold change was used as our cut-off magnitude for gene list compositions by using Excel software.

Proliferation assays. To study the effect of naltrexone on cell growth, cells growing exponentially were added to 96-well plates at a density of $3 \times 10^{4} /$ well. LDN and/or NTX was then added to the wells, ensuring an equal volume of $200 \mu \mathrm{l}$ across the plate. Cell number was measured at $72 \mathrm{~h}$ using a standard methylthiazoltetrazolium (MTT)-based assay as described previously (16).

Immunoblotting analysis. Following individual treatments, cells were then harvested by scraping into lysis buffer (New England Biolabs, Hitchin, UK), and standard western blot protocols were followed as described previously (16). Primary probing was performed with specific antibodies generated against p21, cyclin D1, cyclin B1, BAD, BAX, phosphorylated (p) AKT, AKT, pERK, ERK and tollip (all New England Biolabs). Anti-GAPDH (New England Biolabs) was used as a loading control. All antibodies were used at a dilution of 1:1,000, followed by the appropriate HRP conjugated secondary antibodies (New England Biolabs) also at a dilution of 1:1,000. Bands were visualised by the SuperSignal chemiluminescent detection system (Thermo Scientific, Northumberland, UK). Densitometry of band intensity was determined using Adobe Photoshop CS3, v10.0 (Maidenhead, UK), and normalised to the loading control.

Recovery studies. A549 and HCT116 cells were seeded into 6 -well plates at a density of $2 \times 10^{5} /$ well and left to adhere overnight. Cells were then cultured with NTX $(1$ and $10 \mu \mathrm{M})$ and LDN (1 and $10 \mathrm{nM}$ ). Drug-containing media was removed after $48 \mathrm{~h}$, and cells were rinsed gently with drug-free medium. Fresh culture medium was then added to the cells with or without naltrexone at their matching concentrations, and incubated for a further $24 \mathrm{~h}$. Cell number and viability were assessed at $48 \mathrm{~h}$ (pre-recovery) and $72 \mathrm{~h}$ (post-recovery), with percentages of live and dead cells being discriminated by trypan blue dye exclusion. Cells were also processed for the determination of cell cycle distribution by flow cytometry utilising the nucleic acid stain propidium iodide (16).

Combination studies. The impact of combining LDN with other chemotherapy agents was tested by culturing cells according to a treatment schedule that involved two phases of treatment. The first phase involved priming with LDN or NTX for $48 \mathrm{~h}$, before treatment with another drug for a further 48 h. A549 and HCT116 cells were seeded into 6-well plates at a density of $2 \times 10^{5} /$ well and left to adhere overnight. Cells were then cultured with $10 \mathrm{nM}$ LDN or $10 \mu \mathrm{M}$ NTX. Drugcontaining media was removed after $48 \mathrm{~h}$, and cells were rinsed gently with drug-free medium. Fresh culture medium that contained CPM, GEM or OXP was then added to the cells. The concentrations of the chemotherapy agents used were 
Table I. Top 20 genes induced by treatment with naltrexone. ${ }^{a}$

\begin{tabular}{|c|c|c|c|c|c|c|c|c|c|c|c|c|c|}
\hline \multicolumn{7}{|c|}{ Reduced in LDN only } & \multicolumn{7}{|c|}{ Increased in LDN only } \\
\hline ILMN ID & Gene & UN & NTX & LDN & NTX:UN & LDN:UN & ILMN ID & Gene & $\mathrm{UN}$ & NTX & LDN & NTX:UN & LDN:UN \\
\hline 1778691 & TIA1 & 429 & 428 & 312 & 1.00 & 0.73 & 2362858 & PILRA & 90 & 95 & 130 & 1.05 & 1.44 \\
\hline 2084073 & $\mathrm{UCN}$ & 192 & 192 & 141 & 1.00 & 0.73 & 1746241 & SDHC & 622 & 585 & 789 & 0.94 & 1.27 \\
\hline 2121816 & GPR137B & 303 & 260 & 188 & 0.86 & 0.62 & 1654217 & MPP2 & 131 & 123 & 164 & 0.93 & 1.25 \\
\hline 2233366 & ASAP1 & 469 & 445 & 344 & 0.95 & 0.73 & 1733859 & DCAF15 & 117 & 117 & 157 & 1.00 & 1.34 \\
\hline 1655614 & DSP & 779 & 701 & 544 & 0.90 & 0.70 & 2344373 & MVP & 201 & 193 & 257 & 0.96 & 1.28 \\
\hline 1702835 & SH3BGRL & 1,337 & 1,214 & 953 & 0.91 & 0.70 & 1701621 & $\mathrm{SCO} 2$ & 633 & 602 & 799 & 0.95 & 1.26 \\
\hline 1708611 & RDX & 969 & 900 & 722 & 0.93 & 0.75 & 2133799 & ACAT2 & $\mathrm{x}$ & 95 & 126 & 1.05 & 1.40 \\
\hline 2111237 & MN1 & 169 & 142 & 111 & 0.84 & 0.66 & 1674337 & FKBP2 & 501 & 566 & 748 & 1.13 & 1.49 \\
\hline 1748093 & PAFAH1B3 & 2,665 & 2,150 & 1,672 & 0.81 & 0.63 & 1768181 & TOR3A & 248 & 309 & 407 & 1.25 & 1.64 \\
\hline 1756685 & DEPDC6 & 167 & 147 & 119 & 0.88 & 0.71 & 1700086 & DOK1 & $\mathrm{x}$ & $\mathrm{x}$ & 117 & $\mathrm{x}$ & 1.30 \\
\hline 2292646 & GAD1 & 371 & 287 & 227 & 0.77 & 0.61 & 2410772 & KEAP1 & 678 & 669 & 866 & 0.99 & 1.28 \\
\hline 1770293 & KLF5 & 174 & 157 & 130 & 0.90 & 0.75 & 1723087 & MDK & 121 & 117 & 151 & 0.97 & 1.25 \\
\hline 3178302 & FNDC3B & 454 & 384 & 314 & 0.84 & 0.69 & 1714181 & MEGF8 & $\mathrm{x}$ & 102 & 1,301 & 1.14 & 1.45 \\
\hline 2257833 & BBS7 & 371 & 331 & 274 & 0.89 & 0.74 & 2410262 & MTMR14 & 234 & 237 & 302 & 1.02 & 1.29 \\
\hline 2347805 & EXOC1 & 418 & 375 & 312 & 0.90 & 0.75 & 1665884 & REP15 & 105 & 110 & 139 & 1.04 & 1.33 \\
\hline 2287157 & DST & 546 & 471 & 392 & 0.86 & 0.72 & 1805990 & BAK1 & 101 & 122 & 155 & 1.20 & 1.53 \\
\hline 1718063 & LIPA & 1,032 & 875 & 726 & 0.85 & 0.70 & 1765523 & TOLLIP & 115 & 118 & 149 & 1.02 & 1.29 \\
\hline 2173004 & RAB8B & 655 & 545 & 451 & 0.83 & 0.69 & 1814200 & BMP2K & 91 & $\mathrm{x}$ & 114 & $\mathrm{x}$ & 1.25 \\
\hline 1806667 & FRAS1 & 918 & 789 & 658 & 0.86 & 0.72 & 1788988 & THAP1 & 177 & 200 & 253 & 1.13 & 1.43 \\
\hline 1758895 & CTSK & 168 & 136 & 113 & 0.81 & 0.67 & 1777584 & KARS & 792 & 824 & 1,038 & 1.04 & 1.31 \\
\hline
\end{tabular}

${ }^{\mathrm{a}} \mathrm{HCT} 116$ cells were treated with LDN (10 nM naltrexone) or NTX (10 $\mu \mathrm{M}$ naltrexone) for $4 \mathrm{~h}$. Cells were then harvested using trypsin, and RNA was extracted using TRIzol ${ }^{\mathrm{TM}}$. Gene expression analysis was performed using the Illumina array system, gene lists for each treatment regimen were generated using Excel, and presented as fold changes from the untreated controls (UN).

$\sim 1 / 4 \mathrm{IC}_{50}$ as established previously (17). Cells were then left for a further $48 \mathrm{~h}$ before cell counting and processing for flow cytometry and western blotting.

\section{Results}

Different patterns of genes are affected by NTX and LDN. Standard unsupervised microarray analysis of the transcriptome of cells following treatment with NTX or LDN was performed to understand the patterns of genes that were altered at the different doses. It also served to possibly identify novel targets of naltrexone, which could explain further the anticancer effects associated with its use.

Following the initial filtering and removal of nonsense genes from the gene microarray chip, 15,012/27,132 (55\%) genes were judged present in at least one of the treatment conditions. Although a large proportion of these were present in all conditions, 12,275/15,012 (82\%) (Fig. 1A), some were unique to a particular condition. We therefore focused next on those genes that, when compared to untreated cells, were specifically altered following treatment with NTX or with LDN (Fig. 1B). The majority of genes that were either downor upregulated were the same irrespective of the treatment being NTX or LDN. However, there was a proportion of genes that changed specifically in response to either NTX or LDN. For example, concentrating on those genes $(n=930)$ that were downregulated by treatment, 448 were common to both NTX and LDN; however, 214 were unique to NTX and 168 to LDN. Full gene lists are available at ArrayExpress (www.ebi.ac.uk accession no. E-MTAB-4454).

A number of gene lists were made that recorded those down- and upregulated by treatment with different doses. Specific examination of the top 20 genes in these lists revealed a number of genes that were of interest to us such as the paired immunoglobin-like type 2 receptor $\alpha$ (PILRA), which is involved in the regulation of the immune system, and the proapoptotic gene $B A K 1$. Both were increased significantly by LDN but not NTX (Table I). This highlighted the possibility that NTX and LDN affect different groups of genes. Therefore, we next used gene ontology (GO) and grouped the genes with changes in their expression according to their molecular function and biological process. Results showed some cross-over in the genes that were altered by the different treatments. We next focussed specifically on the groups of genes that were uniquely altered by NTX or LDN, and we saw that a number of the GO-categories that were upregulated exclusively by LDN were associated with cell cycling (Fig. 1B-b). This directed us to specifically examine genes that directly regulated the 
A

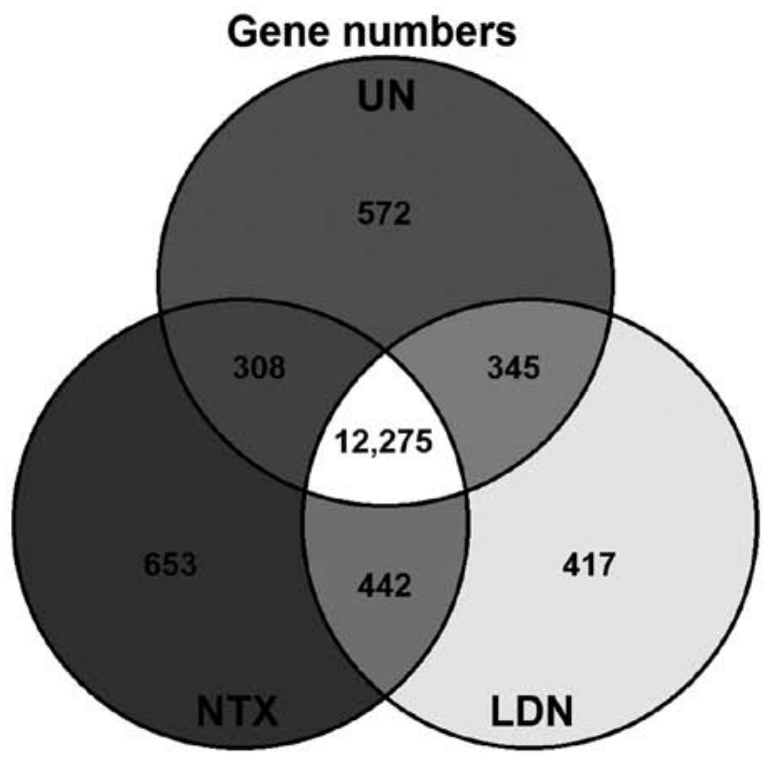

B a Down-regulated genes

Bb

Up-regulated genes
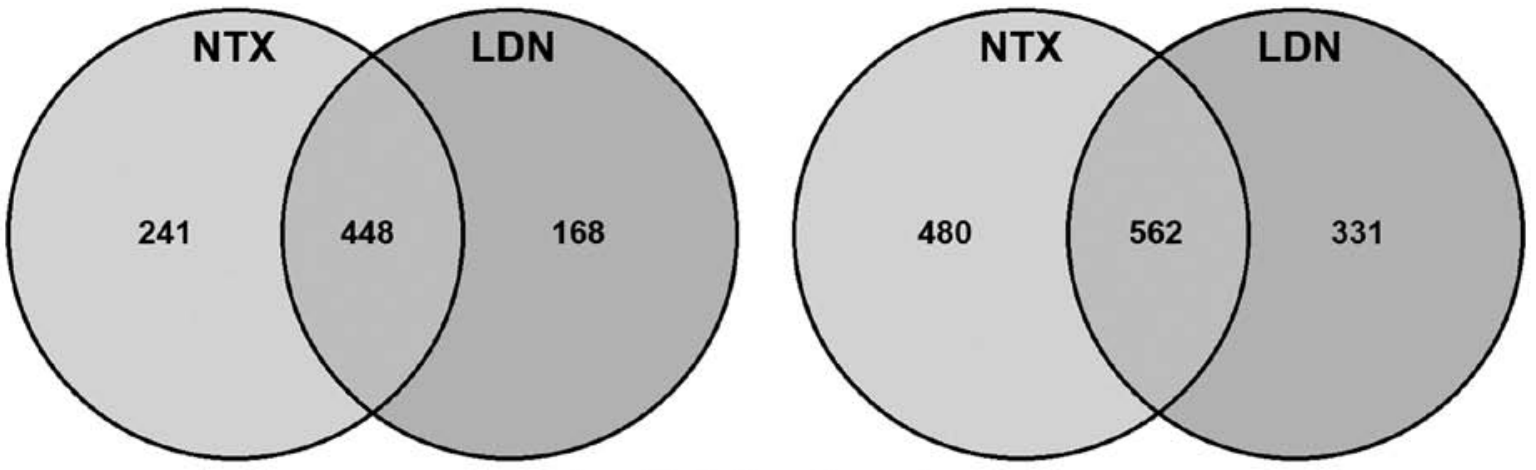

Top 10 GO-categories

\begin{tabular}{|c|c|c|}
\hline Lysosome & Glycolysis & Cytoplasm \\
\hline Plasma membrane & Response to hypoxia & Plasma membrane \\
\hline Blood coagulation & Cytoplasm & Nucleotide binding \\
\hline $\begin{array}{l}\text { Substrate adhesion- } \\
\text { dependent cell spreading }\end{array}$ & Metabolic process & $\begin{array}{l}\text { Carbohydrate metabolic } \\
\text { process }\end{array}$ \\
\hline Metabolic process & Gluc & Metabolic process \\
\hline Membrane & & ATP binding \\
\hline $\begin{array}{l}\text { Interferon-gamma- } \\
\text { meciated signaling } \\
\text { pathway }\end{array}$ & Basal lamina & $\begin{array}{l}\text { Negative regulation of } \\
\text { translation }\end{array}$ \\
\hline $\begin{array}{l}\text { Cytokine-mediated } \\
\text { signaling pathway }\end{array}$ & Cell adhesion & Glucose metabolic process \\
\hline Endoplasmic reticulum & $\begin{array}{l}\text { Multicellubar organismal } \\
\text { development }\end{array}$ & Phosphorylation \\
\hline ction & L-ascorbic acid binding & $\begin{array}{l}\text { Positive regulation of fat } \\
\text { cell differentiation }\end{array}$ \\
\hline
\end{tabular}

\begin{tabular}{|c|c|c|}
\hline Nucleus & Nucleus & Nucleus \\
\hline Cytoplasm & Mitotic cell cycle & Nucleoplasm \\
\hline Cytosol & Nucleoplasm & Mitotic cell cycle \\
DNA replication & Cell cycle \\
\hline Mitotic cell cycle & Cell cycle & Cell dvision \\
\hline Cell cycle & Cytoplasm & Cytoplasm \\
\hline Nucleolus & $\begin{array}{c}\text { G1-S transition of mitotic } \\
\text { cell cycle }\end{array}$ & Mitosis \\
\hline Cell cycle checkpoint & Nucleolus & Metabolic process \\
\hline Cell division & Cytosol & DNA repair \\
\hline Nucleotide binding & Sphase of mitotic cell \\
cycle & DNA replication \\
\hline Nucleoplasm & & \\
\hline
\end{tabular}

\section{Top 10 unique GO-categories}

\begin{tabular}{|c|c|c|}
\hline $\begin{array}{l}\text { Substrate adhesion } \\
\text { dependent cell spreading }\end{array}$ & Glycolysis & Nucleotide binding \\
\hline Platelet activation & Response to hypoxia & ATP binding \\
\hline Regulation of angiogenesis & Basal lamina & $\begin{array}{l}\text { Negative regulation of } \\
\text { translation }\end{array}$ \\
\hline $\begin{array}{l}\text { Hydrolase activity on } \\
\text { glycosyl bonds }\end{array}$ & L-ascorbic acid binding & Phosphorylation \\
\hline Visual learning & Embryo implantation & $\begin{array}{l}\text { Positive regulation of fat } \\
\text { cell differentiation }\end{array}$ \\
\hline $\begin{array}{l}\text { Positive regulation of } \\
\text { canonical Wnt pathway }\end{array}$ & $\begin{array}{l}\text { Negative regulation of } \\
\text { transcription from RNA pol- } \\
\text { II }\end{array}$ & Homophïic cell adhesion \\
\hline JAK-STAT cascade & Collagen & Glycogen catabolic process \\
\hline $\begin{array}{l}\text { Positive regulation of } \\
\text { protein ubiquitination }\end{array}$ & Cell surface & Actin filament organization \\
\hline Kininogen binding & $\begin{array}{l}\text { Nervous system } \\
\text { development }\end{array}$ & Transferase activity \\
\hline Platelet degranulation & Gluconeogenesis & $\begin{array}{l}\text { Galactose catabolic } \\
\text { process }\end{array}$ \\
\hline
\end{tabular}

\begin{tabular}{|c|c|c|}
\hline $\begin{array}{l}\text { Regulation of transcription } \\
\text { from RNA pol-II }\end{array}$ & Nucleotide-excision repair & Cell cycle arrest \\
\hline $\begin{array}{c}\text { Single-stranded DNA } \\
\text { binding }\end{array}$ & mRNA processing & $\begin{array}{c}\text { G1 phase of mitotic cell } \\
\text { cycle }\end{array}$ \\
\hline $\begin{array}{l}\text { Regulation of cellular } \\
\text { amino acid metabolic } \\
\text { process }\end{array}$ & $\begin{array}{l}\text { Transcription-coupled } \\
\text { nucleotide-excision repair }\end{array}$ & Response to drug \\
\hline Exoribonuclease activity & Centrosome & Mitochondrial matrix \\
\hline Proteasome complex & $\begin{array}{l}\text { Condensed nuclear } \\
\text { chromosome }\end{array}$ & $\begin{array}{c}\text { Regulation of catalytic } \\
\text { activity }\end{array}$ \\
\hline Exosome (RNase complex) & $\begin{array}{l}\text { Condensed chromosome } \\
\text { kinetochore }\end{array}$ & $\begin{array}{l}\text { Cyclin-dependent protein } \\
\text { kinase inhibitor activity }\end{array}$ \\
\hline Nuclear mRNA surveillance & $\begin{array}{l}\text { Telomere maintenance via } \\
\text { semi-conservative } \\
\text { replication }\end{array}$ & Cytokinesis \\
\hline $\begin{array}{l}\text { ATP-dependent DNA } \\
\text { helicase activity }\end{array}$ & $\begin{array}{c}\text { Telomere maintenance via } \\
\text { recombination }\end{array}$ & $\begin{array}{l}\text { Transcription initiation from } \\
\text { mitochondrial promoter }\end{array}$ \\
\hline Damaged DNA binding & Ligase activity & $\begin{array}{l}\text { Negative reguiation of } \\
\text { cyclin-dependent protein } \\
\text { kinases }\end{array}$ \\
\hline $\begin{array}{l}\text { DNA damage response, } \\
\text { signal transduction by p53 }\end{array}$ & $\begin{array}{l}\text { Nucleobase, nucleoside } \\
\text { and nucleotide metabolism }\end{array}$ & Protein kinase binding \\
\hline
\end{tabular}

Figure 1. Effect of NTX and LDN on gene expression. HCT116 cells were treated with LDN (10 nM naltrexone) or NTX (10 $\mu$ M naltrexone) for 4 h. Cells were then harvested using trypsin, and RNA was extracted using TRIzol ${ }^{\mathrm{TM}}$. Gene expression analysis was performed using the Illumina array system, and genes separated into GO-categories by using Pathway Studio. The spread of the numbers of genes called present following treatment are presented in (A). Those genes specifically downregulated (B-a) or upregulated (B-b) by the treatment were categorised. Some of these categories were unique to a particular treatment, and identified in the tables. 
Table II. Effect of NTX and LDN on cell cycle-related genes in HCT116 cells. ${ }^{\mathrm{a}}$

\begin{tabular}{|c|c|c|c|c|c|c|c|}
\hline \multirow[b]{2}{*}{ Process } & \multirow[b]{2}{*}{ Gene } & \multicolumn{3}{|c|}{ Raw data } & \multicolumn{3}{|c|}{ Relative to UN } \\
\hline & & UN & NTX & LDN & NTX/UN & LDN/UN & LDN/NTX \\
\hline DNA damage & $\mathrm{p} 53$ & 271 & 257 & 251 & 0.95 & 0.93 & 0.98 \\
\hline \multirow[t]{7}{*}{ CDKi } & $\mathrm{p} 21$ & 2,022 & 1,780 & 1,776 & 0.88 & 0.88 & 1.00 \\
\hline & $\mathrm{p} 27$ & 441 & 400 & 398 & 0.91 & 0.90 & 0.99 \\
\hline & p57 & 211 & 161 & 171 & 0.77 & 0.81 & 1.06 \\
\hline & p19 & 202 & 246 & 262 & 1.22 & 1.30 & 1.07 \\
\hline & p18 & 91 & 92 & - & 1.02 & - & - \\
\hline & p16 & 198 & 234 & 246 & 1.18 & 1.24 & 1.05 \\
\hline & $\mathrm{p} 15$ & 153 & 137 & 133 & 0.90 & 0.87 & 0.97 \\
\hline \multirow[t]{2}{*}{ G0 } & cy C & 669 & 729 & 696 & 1.09 & 1.04 & 0.95 \\
\hline & CDK3 & 93 & 98 & 91 & 1.06 & 0.98 & 0.93 \\
\hline \multirow[t]{5}{*}{ G1 (early) } & cy D1 & 6,580 & 6,773 & 6,574 & 1.03 & 1.00 & 0.97 \\
\hline & cy D2 & 95 & 96 & 91 & 1.01 & 0.96 & 0.95 \\
\hline & cy D3 & 1,247 & 1,542 & 1,511 & 1.24 & 1.21 & 0.98 \\
\hline & CDK4 & 3,528 & 3,541 & 4,345 & 1.00 & 1.23 & 1.23 \\
\hline & CDK6 & 550 & 682 & 768 & 1.24 & 1.40 & 1.13 \\
\hline \multirow[t]{3}{*}{ G1 (mid) } & cy E1 & 357 & 453 & 455 & 1.27 & 1.27 & 1.00 \\
\hline & cy E2 & 491 & 804 & 766 & 1.64 & 1.56 & 0.95 \\
\hline & CDK2 & 765 & 974 & 989 & 1.27 & 1.29 & 1.02 \\
\hline \multirow[t]{2}{*}{ S } & cy A2 & 1,473 & 1,933 & 2,040 & 1.31 & 1.38 & 1.06 \\
\hline & CDK2 & 765 & 974 & 989 & 1.27 & 1.29 & 1.02 \\
\hline \multirow[t]{4}{*}{ M } & cy B1 & 1,528 & 1,715 & 1,919 & 1.12 & 1.26 & 1.12 \\
\hline & cy B2 & 2,530 & 2,686 & 2,806 & 1.06 & 1.11 & 1.04 \\
\hline & cy B3 & 105 & 97 & 96 & 0.93 & 0.92 & 0.99 \\
\hline & CDK1 & 1,016 & 1,378 & 1,207 & 1.36 & 1.19 & 0.88 \\
\hline
\end{tabular}

${ }^{a}$ Cells were treated with LDN (10 nM naltrexone) or NTX (10 $\mu \mathrm{M}$ naltrexone) for $4 \mathrm{~h}$. Cells were then harvested using trypsin, and RNA was extracted using TRIzol. Gene expression analysis was performed using the Illumina array system, and only genes related to cell cycle control and called present in at least one treatment included in the lists. Genes were categorised based upon cell cycle phase, and those altered by $>10 \%$ in either direction are in bold.

cell cycle to see if there was any divergence of changes in them caused by treatment with LDN or NTX. Results showed they were generally altered by a similar magnitude through treatment with both NTX and LDN; however, there were four exceptions, in that CDK1, 4, 6 and cyclin B1 were affected differently (Table II).

NTX and LDN alter the expressions of key proteins. To confirm and assess the effects that treatments had on targets identified by the microarray screen, western blotting was performed on whole cell lysates harvested from HCT116 cells treated with NTX or LDN. The choice of proteins that were assessed was guided by the lists from the microarray expression data, and selected upon the basis of the magnitude of their differential expressions. Results indicated that the selective increases in some cell cycle related genes following treatment with LDN were recapitulated by increased protein expression (Fig. 2). Other notable proteins that corresponded with the gene data included BAD and TOLLIP, which were increased following culture with LDN but not with NTX. These were notable as both were involved in determining the level of cell death by regulating apoptosis and autophagy, respectively. AKT and ERK were also prospectively included as a way of assessing the general signalling status of the cell, and results indicated that they were impacted upon to a similar magnitude by NTX and LDN.

A break in treatment (recovery phase) enhances the cytotoxic effect of $L D N$. MTT assays were used to assess the effect of naltrexone on a variety of cell lines from different tissues, and results showed the effect on cell numbers was minimal. Extrapolated $\mathrm{IC}_{50}$ concentrations for all the cell lines were $>100 \mathrm{M}$ (Fig. 3A). Our previous studies have shown that the cytotoxicity of some agents can be increased by employing a break in treatment, the effect of which is associated with disturbances in cell cycling dynamics $(16,18,19)$. As cell cycling has been implicated as being important in this study, we next tested the possibility that a recovery phase may 
p21

UN NTX LDN
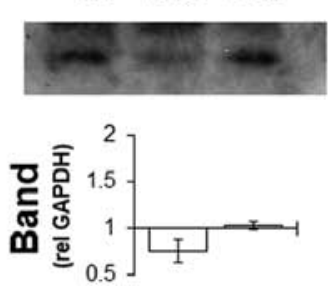

PAKT

UN NTX LDN
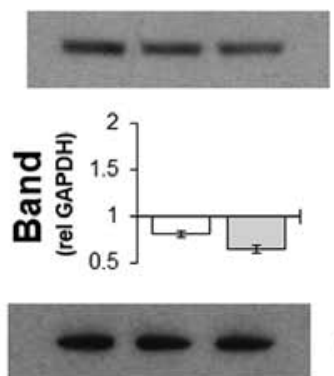

Cyclin D1
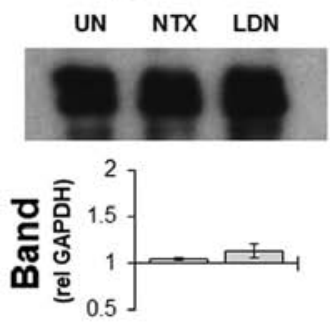

AKT
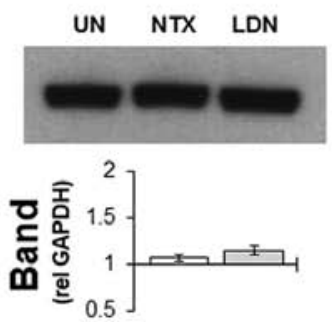

GAPDH
Cyclin B1
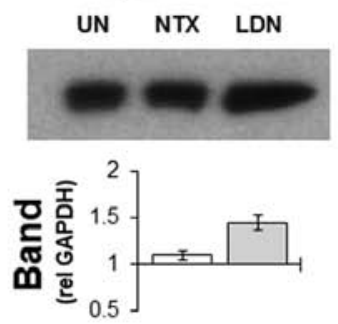

PERK

UN NTX LDN
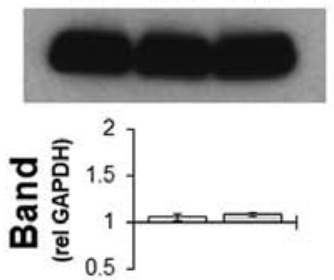

BAD

BAX
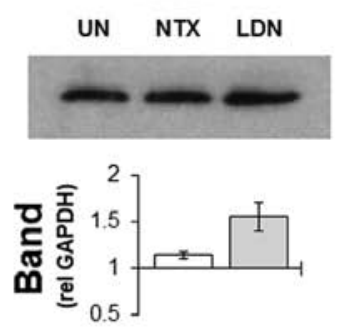

ERK
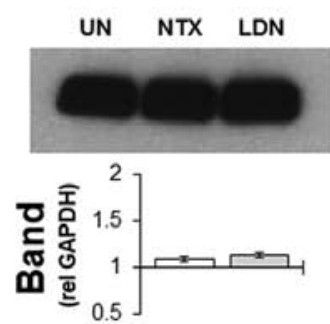

UN NTX LDN
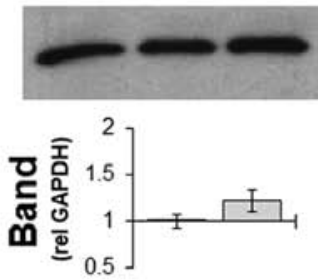

TOLLIP

UN NTX LDN
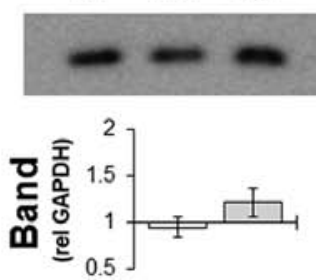

Figure 2. Effect of NTX and LDN on a collection of proteins in HCT116 cells. Cells were treated with LDN (10 nM naltrexone) or NTX (10 $\mu$ M naltrexone) for $24 \mathrm{~h}$. Cells were then harvested by scraping and lysed in RIPA buffer for western blot analysis. Selection of the proteins was guided in part by the gene expression data. Blots are representative of three separate experiments, and the densitometry represents the mean and SDs of these expressed relative to the respective GAPDH loading control.

A
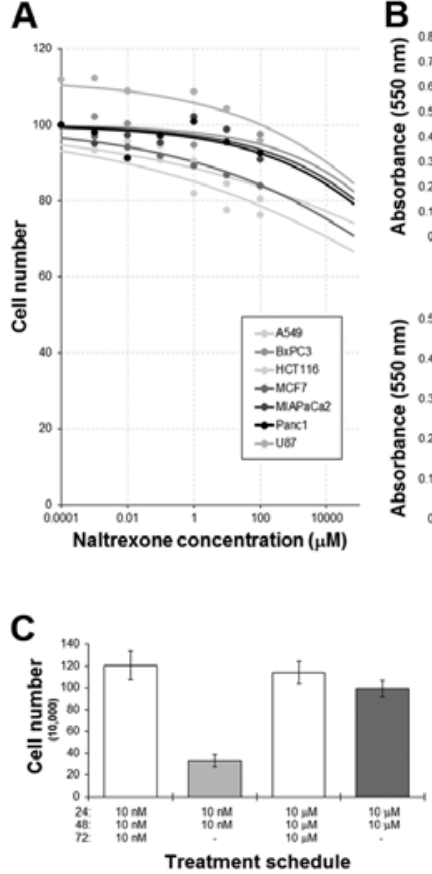
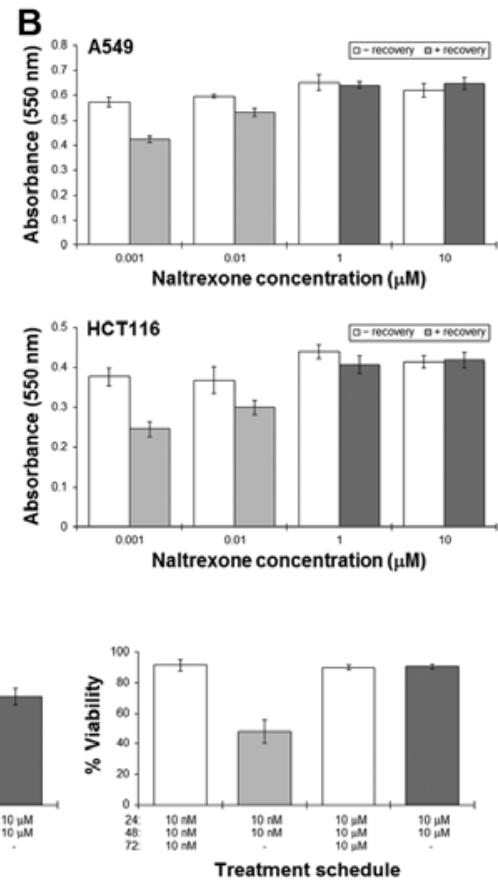
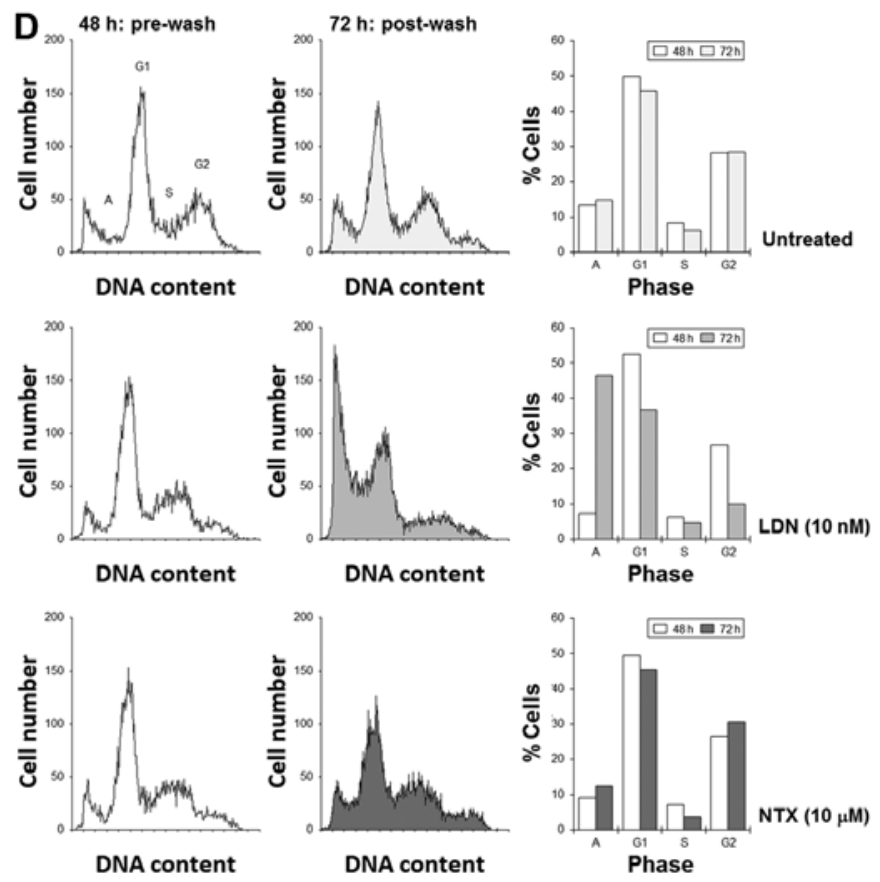

Figure 3. Effect of a drug-free period following culture with LDN or NTX. First the effect of a 72-h exposure to naltrexone was tested on a panel of cell lines and shown to be ineffectual at reducing cell numbers (A). A549 and HCT116 cells were then cultured with naltrexone at $1 \mathrm{nM}, 10 \mathrm{nM}, 1 \mu \mathrm{M}$ and $10 \mu \mathrm{M}$. The first two concentrations were designated as LDN whilst the last two were conventional concentrations (NTX). After 48 h, media were aspirated and cells washed and re-cultured drug-free medium for a further $24 \mathrm{~h}$. Parallel cultures were set up where cells were returned to drug-containing medium. MTT analysis (B) and cell counting using trypan-dye exclusion were performed on the cells (C - HCT116 alone). FACS analysis at 48 and $72 \mathrm{~h}$ were also done on HCT116 cells in an attempt to establish cell cycle distribution (D).

enhance cell killing. A549 and HCT116 cells were cultured with LDN or NTX for $48 \mathrm{~h}$, at which time, the drug-containing medium was removed and the cells then allowed to recover in drug-free medium for a further $24 \mathrm{~h}$. 

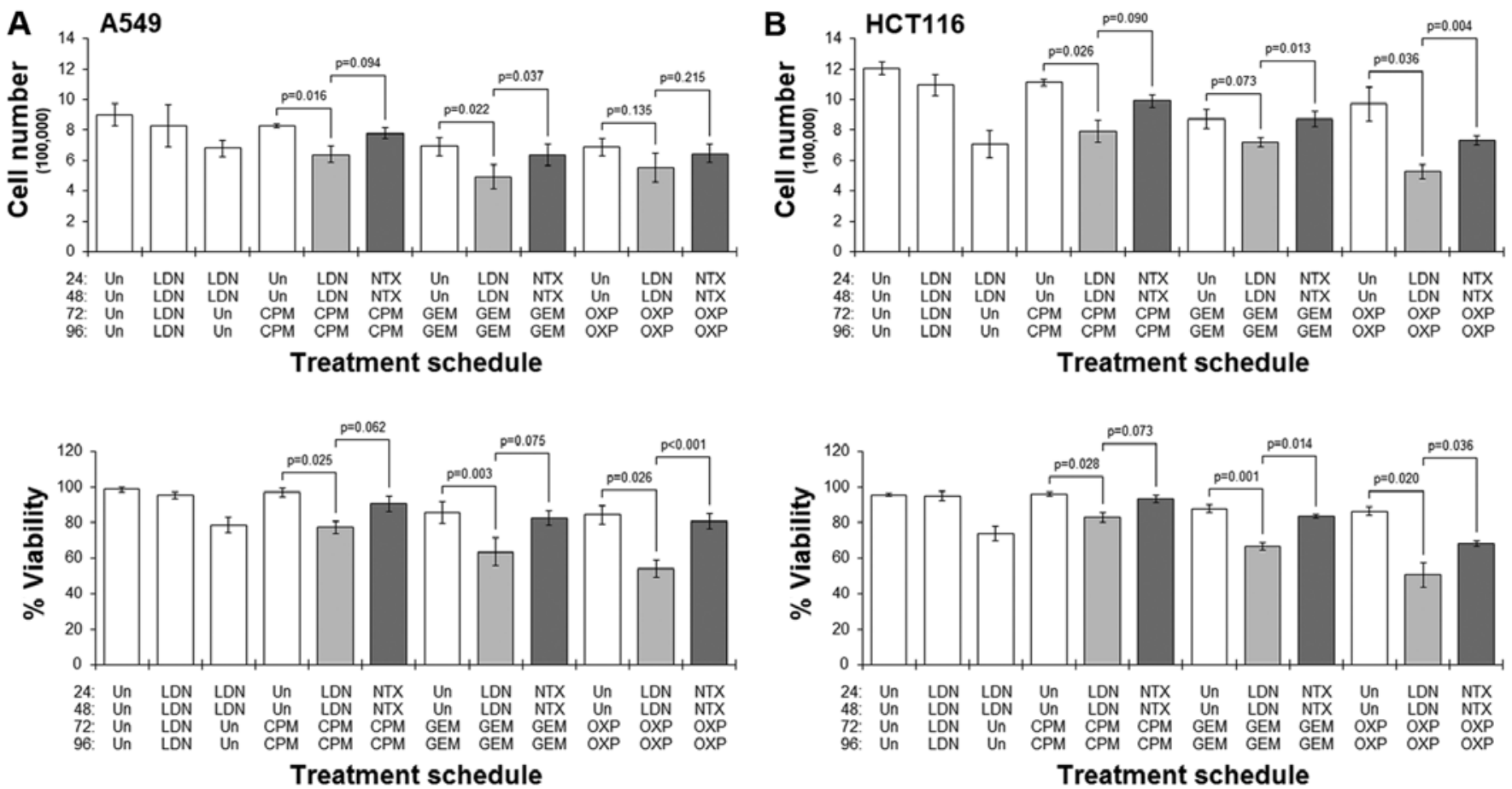

Figure 4. Effect of priming with LDN or NTX on A549 and HCT116 cells. Cells were cultured with 10 nM naltrexone (LDN) or $10 \mu$ M naltrexone (NTX) for $48 \mathrm{~h}$ before replacing the exhausted media with fresh media supplemented with cyclophosphamide (CPM, $100 \mu \mathrm{M}$ for both cell lines), gemcitabine (GEM: $0.5 \mu \mathrm{M}$ for both cell lines) or oxaliplatin (OXP, $1 \mu \mathrm{M}$ for both). Cells were allowed to grow for another $48 \mathrm{~h}$ before assessing cell number and viability. Columns represent the means and SDs of three separate experiments. P-values are from paired Student's t-tests following analysis of variance to determine differences within the groups.

MTT assays showed significant reductions in the number of A549 and HCT116 cells remaining when a 'recovery' phase was adopted into the LDN treatment schedules (Fig. 3B). An initial culture with NTX did not result in such a dramatic reduction in cell number. Cell counting experiments in HCT116 cells revealed that the reduction in cell number was associated with a fall in cell viability, which suggested an active cytotoxic response was achieved (Fig. 3C). Additional flow cytometric analysis of the cell cycle showed significant increases in the sub-G1 (apoptosis) peak following a LDN-then-recovery schedule with concomitant emptying of cells from G1 and G2. This was not as pronounced with NTX (Fig. 3D).

Priming cells with LDN enhances the activity of chemotherapy. Having shown that the pro-apoptotic proteins BAX and BAD were upregulated following treatment with LDN, we next tested the possibility that priming cells with LDN could sensitise cells to common chemotherapy drugs. We assessed this by developing treatment schedules that were made up of two separate treatment phases. The first would last $48 \mathrm{~h}$ and comprise no treatment or treatment with LDN. After this time, cells were removed from the drug, and the second phase of treatment would be added. This would also last $48 \mathrm{~h}$, and be CPM, GEM or OXP. As a comparison, we also performed parallel experiments in which we used NTX in the first treatment phase.

Results showed that in both cell lines studied, pre-culture with LDN followed by culture with any of the drugs always resulted in a greater reduction in cell number and viability when compared to the corresponding schedule that did not have the LDN pre-culture (Fig. 4). Conversely, in those schedules where cells were pre-cultured with standard NTX, treatment with any of the cytotoxic drugs did not generally result in dramatic reductions in cell number or viability (Fig. 4). Furthermore, comparing LDN-priming schedules with their respective NTX-primed ones showed significantly better cytotoxicity in the former schedules.

\section{Discussion}

Evidence of a role for naltrexone as an anticancer agent has been described in the literature for some time. Studies have highlighted an ability of this opioid antagonist to impede the rate and way that cancer cells grow, and that these anticancer action occur only at lower doses. However, the mechanism of this action has yet to be fully defined, and as such, the true value of this drug in the oncological setting has yet to be established in the clinical community. In an attempt to shed more light on this area, we have performed gene microarray studies to ascertain the means by which naltrexone can disrupt tumour cell growth. Additionally, we have compared the genetic fingerprint of tumour cells treated either with LDN or NTX to evaluate whether there is a divergence in the actions of the treatments. The significant finding of this study has been the categories of genes that are unique to LDN, which suggests that the mode of action differs between LDN and NTX.

In the early 1960s, it was reported that morphine possessed the capacity to disrupt the normal physiology of tumour-bearing rats (20). The study was undertaken primarily to explore the appetite-disruptive nature of morphine on animals bearing 
tumours; however, in addition to showing the morphine could reduce the body-weights of these animals, it was also noticed that their tumour-weights were concomitantly increased. The reason for this increase in tumour size was unclear, but it was perceivable that morphine could have had secondary effects on the immune system that supported tumour progression (21). Alternatively, the increases in tumour size could simply have been due to a direct effect of morphine that resulted in enhanced cellular proliferation in the tumours or reduced cell death. Indeed, morphine has been shown to prevent the normal cell death in the ciliary ganglion of the chick embryo, suggesting that in addition to modulating neurotransmission, it and other endogenous opiates may also regulate neurophysiology (22). The concentration of morphine appeared to be important in which effect it caused, as apoptosis in the chick embryo was only disrupted when used at the higher doses, whilst no effect was seen at the lower doses (6). Taken together, this suggested the possibility that drugs of this class could be used therapeutically to reduce tumour growth.

In fact, a similar growth-inhibitory action has been reported for the antagonist naltrexone, which also exhibits a similar dose-dependent quality (1). The mechanism by which it exerts its anticancer effect has yet to be fully elucidated, but a number of reports have indicated both direct-effects on tumour as well as indirect modifications to immune function, which enhances host immunity against tumours. Naltrexone has also been reported to elicit a number of other cellular responses that lead to reductions in tumours. Therefore, an agent that can alter survival and growth characteristics of cancer cells directly, whilst simultaneously promote an anticancer response by the immune system is attractive as a putative therapy (23).

In the first part of the study, we employed gene expression microarrays to identify the transcripts that were altered following culture with naltrexone. As previous studies, which included our own, acknowledged a possible divergence in effects dependent upon dose, we assessed and compared the effects of a low dose of naltrexone (LDN) with a more standard concentration (NTX). Although LDN and NTX are essentially the same drug, albeit at different concentrations, results showed approximately half of the genes that were altered following treatment with either were not the same. We thus focussed only on these, and surveyed the profile more carefully by using gene ontology. Results showed that the types of genes being downregulated by treatment were variable, and no categories of genes emerged as being prevalent. In contrast, the categories of genes that were upregulated by treatment were associated with regulation of the cell cycle. To get a perspective of whether specific classes of genes were impacted upon by LDN and not NTX, we next focussed on the genes that were altered uniquely by LDN. Results showed that the common categories affected by LDN and not NTX were those involved with the cell cycle.

A typical response to cellular and/or DNA damage as a consequence of drug activity is to induce a cell cycle arrest that allows for the cell to decide a response (24). Typically, this arrest is transient and cells rapidly undergo repair or enter the apoptosis program. However, in some cases, this arrest persists, and the cells enter a protracted state of cytostasis (25), which can be inadvertently maintained by the presence of the drug. This paradoxically reduces the net sensitivity of the cell to the treatment. Cell death systems are intricately linked with those that regulate cell cycling, which means that the ability to perform one requires the ability to perform the other (26). Therefore, a protracted blockade in the cell cycle can minimise the ability of cells to undergo cell death.

Naltrexone has been described to exhibit a similar quality. One animal study from the 1980s reported the importance of the naltrexone dose in determining the overall antitumour effect. It was reported that, specifically for naltrexone, treatment in mice with a clinically conventional dose $(10 \mathrm{mg} / \mathrm{kg})$ induces a continuous occupancy of the opioid receptors, to which it is known to bind, which resulted in increased tumour growth (27). However, if doses were reduced to 1 or $0.1 \mathrm{mg} / \mathrm{kg}$, the receptor blockade was thought to be incomplete, and binding sites remained open to ligands and thus activation of antitumour processes.

Subsequent studies have also hinted at the importance of treatment schedule in determining efficacy, with intermittent administration of lower concentrations of naltrexone achieving the greatest antitumour response (28). Antagonistic blockade of the opioid receptors has been shown to result in a compensatory increase in their amounts. The immediate consequence of this would be a boost in receptors to which endogenous ligands such as the opioid growth factor (OGF) could bind. OGF binding would ultimately result in an inhibition of growth (1). This feedback-like benefit is lost if naltrexone was left in culture, as the continued presence of naltrexone occupies the de novo binding sites and out-compete OGF. Thus no growthinhibitory effect would be achieved.

Taken together, we hypothesised that adopting a recovery phase, during which time the cells would be devoid of drug, could result in improved efficacy. Results of the current experiments supported this, which showed that removing the cells from the culture medium containing LDN and allowing them to grow in drug-free medium significantly increased cell death. There are precedents for this; in fact, we have recently shown with other drugs that exhibit this protracted cell cycle blockade character that cell death can be enhanced by introducing a drug-free phase in the treatment schedule $(16,19)$. These studies showed that drugs such as artemisinin and cannabidiol can elicit cell death in a number of cancer cells; however, in a number of these cases, their use has been associated with an absence of active cell killing. Instead, cells have arrested for much longer. Although the accompanying reduction in cell number is welcome, the lack of an active 'cell killing' reaction is not. One way around this is to include a drug-free phase, which can significantly enhance the cytotoxic nature of the treatments.

Our gene expression analysis also indicated a number of pro-apoptotic genes were upregulated by LDN. For example, the genes for bcl2-antagonist/killer 1 (BAK1) and the bcl2associated X protein (BAX) were both increased after treatment with LDN but not after NTX. This disparity in gene expression was recapitulated at the protein level, and offered the notion that treating tumour cells with LDN may prime cells to apoptosis (29). We therefore tested this by culturing cells with LDN before introducing them to a common cytotoxic drug. Results indicated the cytotoxic effects of the chemotherapies tested were significantly improved when cells were pre-treated with LDN, whilst pre-treatment with NTX did not result in such a 
drastic response. Parenthetically, as the act of removing LDN could account for the increase in activity, paired t-test analysis were performed, which showed significant differences when comparing some of the schedules with the LDN:Un schedules.

The idea that LDN can prime a cancer cell to the effect of an 'old-school' cytotoxic drug is attractive (30), and presents a way that treatment regimens could be developed to exploit this potential mutualistic effect. Indeed, we have illustrated how the essence of combination therapy is to bring together drugs that have connected mechanisms of action, which when used together, generates an effect that surpasses what would have been achieved if the individual drugs were used separately (11). Improvements to outcome could equally be a consequence of a priming effect as seen in this study. It is also worthwhile noting that the drugs in the partnership do not need to be related, and one only has to induce an effect that sensitises the cell to the other drug. These combinations also usually involve a particular sequence of administration, with the priming drug given first. Our results thus suggest that LDN is a potential partner in drug-treatment regimens, and should be given upfront before common cytotoxic agents. The detailed molecular basis of this LDN-drug interaction needs to be fully assessed to ensure that the most appropriate combinations are identified. Unlike many other drugs used in oncology, LDN is non-toxic and relatively cheap.

In conclusion, these data highlight the existence of a fundamental difference in the mechanism by which naltrexone elicits an effect. By using gene expression analysis, we showed there was a difference in the gene-fingerprint of the drug when used at two different concentration ranges. Specifically, LDN resulted in explicit changes to genes involved in cell cycle control, which were absent when doses were much higher. Further experimentation that was steered by the gene data revealed the efficacy of LDN to be enhanced by adaptations to treatment schedules. These improvements were linked to our attempts to negate a cell cycle and/or cell death blockade caused by the presence of the drug. Additionally, by utilising the priming effect of LDN, the cytotoxic effect of common chemotherapy drugs could be increased through the sequential administration of the drugs. Overall, these studies provide further evidence to support to role of LDN as an anticancer agent.

\section{Acknowledgements}

The authors would like to acknowledge the use of equipment located in the Medical Biomics Centre at St. George's, University of London. Full data records for the gene data are available at ArrayExpress (www.ebi.ac.uk - accession no. E-MTAB-4454). W.M.L. was supported in part by the Cancer Vaccine institute. W.M.L. and A.G.D. are listed as inventors on a patent that describes the use of LDN as an anticancer agent.

\section{References}

1. McLaughlin PJ and Zagon IS: Duration of opioid receptor blockade determines biotherapeutic response. Biochem Pharmacol 97: 236-246, 2015.

2. Tegeder I and Geisslinger G: Opioids as modulators of cell death and survival - unraveling mechanisms and revealing new indications. Pharmacol Rev 56: 351-369, 2004.
3. Afsharimani B, Cabot P and Parat MO: Morphine and tumor growth and metastasis. Cancer Metastasis Rev 30: 225-238, 2011.

4. Gach K, Szemraj J, Stasikowska-Kanicka O, Danilewicz M and Janecka A: Opioid-receptor gene expression and localization in cancer cells. Cent Eur J Biol 6: 10-15, 2011.

5. Bimonte S, Barbieri A, Palma G and Arra C: The role of morphine in animal models of human cancer: Does morphine promote or inhibit the tumor growth? BioMed Res Int 2013: 258141, 2013.

6. Kim MS, Cheong YP, So HS, Lee KM, Kim TY, Oh J, Chung YT, Son Y, Kim BR and Park R: Protective effects of morphine in peroxynitrite-induced apoptosis of primary rat neonatal astrocytes: Potential involvement of $\mathrm{G}$ protein and phosphatidylinositol 3-kinase (PI3 kinase). Biochem Pharmacol 61: 779-786, 2001

7. Cui Y, Zhang XQ, Cui Y, Xin WJ, Jing J and Liu XG: Activation of phosphatidylinositol 3-kinase/Akt-mammalian target of Rapamycin signaling pathway in the hippocampus is essential for the acquisition of morphine-induced place preference in rats. Neuroscience 171: 134-143, 2010.

8. Gach K, Wyrębska A, Fichna J and Janecka A: The role of morphine in regulation of cancer cell growth. Naunyn Schmiedebergs Arch Pharmacol 384: 221-230, 2011.

9. Ishikawa M, Tanno K, Kamo A, Takayanagi Y and Sasaki K: Enhancement of tumor growth by morphine and its possible mechanism in mice. Biol Pharm Bull 16: 762-766, 1993.

10. Boland JW, McWilliams K, Ahmedzai SH and Pockley AG: Effects of opioids on immunologic parameters that are relevant to anti-tumour immune potential in patients with cancer: A systematic literature review. Br J Cancer 111: 866-873, 2014.

11. Liu WM: Enhancing the cytotoxic activity of novel targeted therapies - is there a role for a combinatorial approach? Curr Clin Pharmacol 3: 108-117, 2008.

12. Liu WM, Laux H, Henry JY, Bolton TB, Dalgleish AG and Galustian C: A microarray study of altered gene expression in colorectal cancer cells after treatment with immunomodulatory drugs: Differences in action in vivo and in vitro. Mol Biol Rep 37: 1801-1814, 2010.

13. Liu WM, Dennis JL, Fowler DW and Dalgleish AG: The gene expression profile of unstimulated dendritic cells can be used as a predictor of function. Int J Cancer 130: 979-990, 2012.

14. Liu WM, Dennis JL, Gravett AM, Chanthirakumar C, Kaminska E, Coulton G, Fowler DW, Bodman-Smith M and Dalgleish AG: Supernatants derived from chemotherapy-treated cancer cell lines can modify angiogenesis. Br J Cancer 106: 896-903, 2012.

15. Scott KA, Dennis JL, Dalgleish AG and Liu WM: Inhibiting heat shock proteins can potentiate the cytotoxic effect of cannabidiol in human glioma cells. Anticancer Res 35: 5827-5837, 2015.

16. Liu WM, Gravett AM and Dalgleish AG: The antimalarial agent artesunate possesses anticancer properties that can be enhanced by combination strategies. Int J Cancer 128: 1471-1480, 2011.

17. Liu WM, Fowler DW, Smith P and Dalgleish AG: Pre-treatment with chemotherapy can enhance the antigenicity and immunogenicity of tumours by promoting adaptive immune responses. Br J Cancer 102: 115-123, 2010.

18. Liu WM, Lawrence AJ and Joel SP: The importance of drug scheduling and recovery phases in determining drug activity. Improving etoposide efficacy in BCR-ABL-positive CML cells. Eur J Cancer 38: 842-850, 2002.

19. Scott KA, Shah S, Dalgleish AG and Liu WM: Enhancing the activity of cannabidiol and other cannabinoids in vitro through modifications to drug combinations and treatment schedules. Anticancer Res 33: 4373-4380, 2013.

20. Sobel H and Bonorris G: Effect of morphine on rats bearing Walker carcinosarcoma 256. Nature 196: 896-897, 1962.

21. Sacerdote P: Opioids and the immune system. Palliat Med 20 (Suppl 1): S9-S15, 2006.

22. Meriney SD, Gray DB and Pilar G: Morphine-induced delay of normal cell death in the avian ciliary ganglion. Science 228: 1451-1453, 1985.

23. Liu WM and Dalgleish AG: The potential beneficial effects of drugs on the immune response to vaccination. Semin Oncol 39: 340-347, 2012.

24. Pietenpol JA and Stewart ZA: Cell cycle checkpoint signaling: Cell cycle arrest versus apoptosis. Toxicology 181-182: 475-481, 2002.

25. Shapiro GI and Harper JW: Anticancer drug targets: Cell cycle and checkpoint control. J Clin Invest 104: 1645-1653, 1999. 
26. Waldman T, Zhang Y, Dillehay L, Yu J, Kinzler K, Vogelstein B and Williams J: Cell-cycle arrest versus cell death in cancer therapy. Nat Med 3: 1034-1036, 1997.

27. Zagon IS and McLaughlin PJ: Naltrexone modulates tumor response in mice with neuroblastoma. Science 221: 671-673, 1983.

28. Donahue RN, McLaughlin PJ and Zagon IS: Low-dose naltrexone targets the opioid growth factor-opioid growth factor receptor pathway to inhibit cell proliferation: Mechanistic evidence from a tissue culture model. Exp Biol Med (Maywood) 236: 1036-1050, 2011.
29. Tudor G, Aguilera A, Halverson DO, Laing ND and Sausville EA: Susceptibility to drug-induced apoptosis correlates with differential modulation of Bad, Bcl-2 and Bcl-xL protein levels. Cell Death Differ 7: 574-586, 2000.

30. Makin G and Dive C: Recent advances in understanding apoptosis: New therapeutic opportunities in cancer chemotherapy. Trends Mol Med 9: 251-255, 2003. 